\title{
ONLINE AND PHYSICAL STORES: DETERMINANT FACTORS INFLUENCING THE PURCHASING DECISION AND CUSTOMER'S SATISFACTION
}

\author{
Alina CARAMAN \\ The Bucharest University of Economic Studies, Bucharest, Romania \\ caramanalina19@stud.ase.ro \\ Maria RACOVIȚA \\ The Bucharest University of Economic Studies, Bucharest, Romania \\ racovitamaria19@stud.ase.ro \\ Ana Alexandra GORA \\ The Bucharest University of Economic Studies, Bucharest, Romania \\ anaalexandra.gora@gmail.com
}

\begin{abstract}
Over the last 20 years, there have been significant changes in the retail sector, which have been mainly influenced by technological advances, that have radically transformed the customer experience. This research contributes to the enrichment of the existing literature by examining new purchasing trends concerning the transition to the online environment caused by the COVID-19 pandemic. For an in-depth understanding of the topic, five determinants of the purchasing decision were identified: informativeness, social presence, sensory marketing, product type and brand trust. This study researched, using multi-line analysis, how these factors influence the customer degree of satisfaction regarding online and physical stores. The main results show that customer satisfaction is differently influenced by these factors, depending on the type of store, namely online or physical. These findings demonstrate that companies should adopt different business strategies, focusing on sensory marketing in physical stores and brand trust, together with informativeness in the online ones.
\end{abstract}

Keywords: customers, decision makers, physical stores, online stores, satisfaction

DOI: https://doi.org/10.24818/beman/2021.S.I.2-04

\section{INTRODUCTION}

In the last 20 years, significant changes have been highlighted in the retail sector, these being primarily influenced by technological advances, that have transformed the shopping experience, both from a 
business perspective and from the customer's point of view (Jain \& Werth, 2019). As a consequence, many retailers had to rethink their business models and use a combination of physical stores and online domains to present an integrated shopping experience. The impact of the COVID-19 pandemic has accelerated the transition to the online environment.

This research analysis data shows how the fourth industrial revolution and the COVID-19 pandemic changed customer behavior in both online and physical stores. The study also aims to identify if the influencing factors that determine customer satisfaction are the same for both types of stores. Current literature on omnichannel marketing and e-commerce does not provide a clear answer to these questions. Few studies are conducted on this topic, and existing ones do not thoroughly address changes in the characteristics that customers consider when deciding to shop. The chosen subject was also influenced by the new restrictions that continue to affect the economic activity environment, which are very important for both customers and sellers.

In the context of the COVID-19 pandemic, consumers were forced to change their behavior, while companies had to transform the current business models in order to survive. As the pandemic affected regions and people differently, the economic impact was also uneven. Employees able to work from home have maintained their jobs and income, accumulating more savings, while being forced to reduce spending on blockages, travel restrictions and health concerns; others lost jobs and income or closed businesses and struggled to pay their bills. Regardless of the category, the immediately consequence of this context is rather obvious: people started to shop online in order to avoid the spread of the virus.

\section{CONCEPTUAL BACKGROUND AND DEVELOPMENT OF RESEARCH HYPOTHESES}

In the context of the COVID-19 pandemic, which continues to persist in most countries, online commerce has become one of the most accessible and safe methods, even for the most inexperienced, to do their shopping, mainly because of the imposition of many restrictions, but also rules on social distancing. Target Corp., an American retailer of products and home appliances, stated that in the first quarter of 2020, online sales increased by over 140\% compared to 2019 (ContentEngine LLC, 2020). Because the priority of shoppers is safe shopping, digital stores represent a necessary element for the survival of businesses. At the same time, physical retails have undergone major changes in their normal operation due to forced closures, reduced working hours and the different behavior of customers at home. For example, malls were severely affected by restrictions on the operation of boutiques, cinemas, gyms and restaurants. Some clothing stores and other retailers even went bankrupt in May 2020 (Jones \& Tyko, 2020). From here, the first hypothesis of this study was deduced:

Hypothesis 1: The pandemic caused shoppers to move their purchases online. 
Regardless of the model in which the stores operate, any economic entity needs sales to survive, and sales are directly proportional to the added value offered to buyers. Thus, identifying the most important factors that determine a buyer to purchase from a store and understanding the variables that bring customer satisfaction are significantly important, because those aspects are strengthening the connection between a company and its customer base, which subsequently leads to positive and impactful results (Hill, Brierley \& MacDougall, 2003). Moreover, according to McNealy (1993), customer satisfaction is the strategic weapon for any type of organization.

According to Al-Alwan and Al-Shirawi (2015), six variables that influence the buyer's intention to purchase products online were identified. These are represented by utility, ease of use, trust, culture, website features, and security. Moreover, the results of this study emphasize that trust and security are the two factors that positively and significantly influence the buyer's decision and their attitude towards online shopping (Al-Alwan \& Al-Shirawi, 2015).

On the other hand, Yan \& Dai (2009) consider that the decision to buy from online stores (websites) and the perception of shoppers is influenced by three elements: the consumer, the product and the website, each of these being divided into several influencing factors. Thus, the specific factors of the consumer that influence the purchase decision in the online environment are the following (Yan \& Dai, 2009): demographic data, personal characteristics, degree of involvement in internet and degree of involvement in online shopping, online shopping experience and degree of product cognition. From the category of product-specific factors that are the subject of online shopping, the purchasing decision could be influenced by (Yan \& Dai, 2009): product standardization, sellers' reputation and credibility, price level, information reliability of commodity and region characteristic of commodity. Regarding the website, the specific factors that could influence the online purchasing decision are (Yan \& Dai, 2009): website's business security, rationality of website design and convenience of transaction on the website.

Edwar, Diansari \& Winawati (2018) consider that online shopping has developed on a global scale due to the growing popularity of the internet, which has led to an increase in the number of users who use the internet to obtain information or to make online shopping. The authors identify 8 factors that could influence the purchasing decision and the degree of satisfaction with online stores, namely (Edwar, Diansari \& Winawati, 2018): e-service quality, price, time, easiness, security, trust, convenience and website quality. The results of this study highlight that among the eight factors that influence the decision to shop online, the most dominant are: trust factor, price factor and time factor (Edwar, Diansari \& Winawati, 2018).

Also, regarding online shopping, Katawetawaraks \& Wang (2011) describe four factors that underline the decision to buy online, namely: convenience (online shopping is available non-stop), information (given the inability of customers to reach products, online sellers typically provide more information about a product, 
information that may underlie the decision to purchase), available products and services (online stores offer a greater variety of products and services from which the buyer can choose), cost and time efficiency (offering more products, online stores give shoppers more chances to compare product prices and choose the most suitable one). Moreover, Katawetawaraks \& Wang (2011) present a series of factors that can hinder the purchase decision in online stores, namely: security, intangibility of online product, social contact and dissatisfaction with online shopping.

In the present research, following an analysis of the purchasing process and the literature (Al-Alwan \& AlShirawi, 2015; Edwar, Diansari \& Winawati, 2018; Katawetawaraks \& Wang, 2011; Yan \& Dai, 2009), 5 factors were considered that could affect the decision of buyers to purchase products, whether we are talking about physical stores or online. Thus, it is considered that the five determining factors of the purchasing decision are:

1. Informativeness (product description, product information, delivery information, etc.).

2. Social presence (reviews, recommendations, 'WOM' (Word of mouth) etc.).

3. Sensory marketing (smells, music, colors, photos, videos, etc.).

4. Product type (is the customer familiar or the product is an innovative one, just out on the market).

5. Brand trust (the belief that the brand will meet certain standards).

According to a study realized by Brynjolfsson et al (2009), women are much more inclined than men to share their shopping experiences through social networks, having a great influence in changing the purchasing decisions of people in the immediate vicinity. Thus, the information becomes more transparent and spreads rapidly, which can increase or decrease the income of retailers, being an advantage that entrepreneurs could use as a marketing strategy through WOM ('Word of the mouth'). Due to this study, which notices a difference between the sexes in relation to the perception of social presence as a determinant of the purchasing decision, hypothesis 2 was proposed:

Hypothesis 2: Determinants of the purchasing decision are perceived differently depending on the person's gender.

At the same time, due to the technological advancement and the pandemic in full condition, the entrepreneurs had to quickly adapt in order to stay in the economic game by changing their strategies regarding the marketing and sales department. This raises the question: which determinants of the purchasing decision are responsible for customer satisfaction and whether these values of influence are similar for both types of stores (physical and online). According to Luo and Bhattacharya (2006), increasing customer satisfaction in the online environment results from the high level of information about products that they identify in the purchase process. Buyers want complete, relevant and clear information on the 
websites they navigate on. In other studies from the scientific literature, it has been shown that trust in the product brand is the main important factor in determining the level of satisfaction. A buyer who trusts the brand will be more satisfied and loyal (Greelane, 2019). Hence, hypothesis 3 was developed:

Hypothesis 3: Determinants of the purchasing decision influence customer satisfaction regarding online stores.

However, some experiences can only be created in a physical store. Elkind (2005) states that most shoppers today face countless options when purchasing an item, so the specific in-store smells, the catchy playlist from the background, the brightness of the room, or simply - sensory experiences, help to highlight the brand and increase the level of customer satisfaction. A real-life example is Starbucks, the world's most popular coffee shop. It has an entire team that selects hits on a monthly basis to play them in its stores and create a pleasant atmosphere. Hypothesis 4 intends to investigate whether existing studies still apply today.

Hypothesis 4: Determinants of the purchasing decision influence customer satisfaction regarding physical stores.

Based on the theoretical discussions, hypotheses 3 and 4 can be summarized in the following conceptual research model (Figure 1):

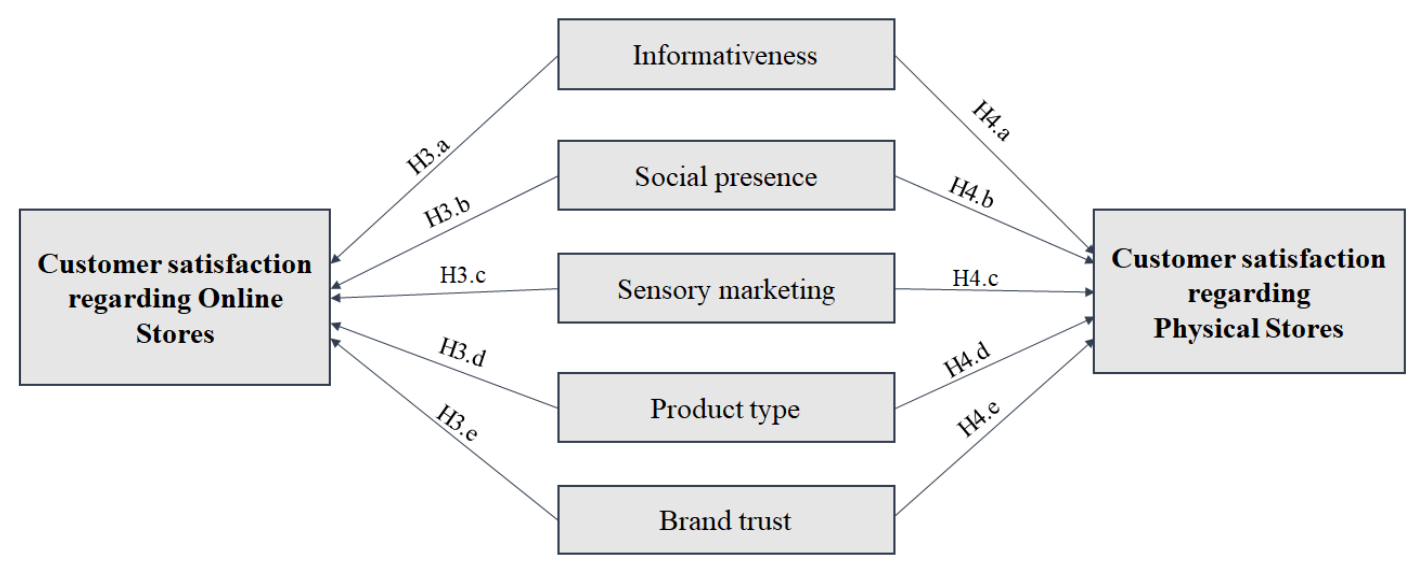

FIGURE 1: CONCEPTUAL MODEL

Source: Created by authors

\section{METHODOLOGY}

\subsection{Data collection}

In order to collect the relevant data for the evaluation of the determinants of the purchasing decision that implicitly influences the customer satisfaction regarding physical and online stores, a questionnaire-based 
survey was conducted. Thus, was developed a questionnaire which was composed of a series of questions that referred to the following aspects: frequency of online shopping before and after the pandemic, security of personal data during the purchase, but also confidence in the online shopping experience, customers' preferences regarding the items they purchase, and the determinant purchase factors that contribute to buyers' satisfaction with their purchase in both physical and online stores. The questionnaire was structured in four sections that allowed the measurement of the research variables concerned, namely:

- Section 1: This first section of the questionnaire covered a series of demographic questions through which the profile of the respondents was determined. The main questions included in this section focused on identifying respondents' gender, occupation, age and monthly income level.

- Section 2: The second section contained a set of questions that determined the buying trends before and after the COVID-19 pandemic.

- Section 3: the third section of the questionnaire consisted of 18 items aimed at identifying the importance assigned by buyers to the five determinants of the purchasing decision and more precisely: informativeness, social presence, sensory marketing, product type, and brand trust.

- Section 4: This section was composed of 22 items through which the level of customer satisfaction regarding online and physical stores was determined.

\subsection{Research population and sample}

The total population of this study is represented by all potential buyers who do their shopping in the online environment or in physical stores, regardless of gender, occupation, age, income or preferences. Regarding the sampling method, non-probabilistic sampling method was used due to the lack of access to a database that would include all potential buyers in our country. In this respect, the final sample of the present research consisted of 125 buyers, of which 40 respondents were men and 85 women. The age of the respondents varied between 18 and over 50 years, and their average incomes were between 500 and over 4500 RON.

\subsection{Procedure}

In order to collect the necessary data to evaluate the determinants of the purchasing decision that influence the degree of customers' satisfaction with purchases in physical and online stores, a questionnaire was developed which was distributed online, using the Google Forms platform. Specifically, this questionnaire was distributed through social networks to people who fell into the above categories. The questionnaire was available for completion for 14 days, in March 2021. For the accuracy of data collection, the questionnaire was preceded by an initial message informing the respondents about the 
purpose of this research and ensuring their anonymity and use of data provided for statistical purposes only. Moreover, with the help of this message, the respondents were also informed about the fact that the completion of the questionnaire is voluntary, as well as about the average time for completing the questionnaire.

Following data collection, the results of this survey were evaluated using statistical methods. The SPSS statistical program was used to analyze the data and test the research hypotheses. With the help of this statistical program, a series of descriptive statistical analyzes were performed, various coefficients were calculated and specific tests for preliminary analyzes were carried out (such as Cronbach Alpha internal consistency coefficient, Levene test, variance inflation factor (VIF)). Then, $t$ tests and multiple linear regression analysis were used to test the research hypotheses to identify the extent to which the five determinants of the purchasing decision (informativeness, social presence, sensory marketing, product typology and brand trust) determine the degree of customer satisfaction regarding the online stores, and respectively the physical ones.

\section{RESULTS AND DISCUSSION}

\subsection{Descriptive Statistics and Preliminary Analysis}

Before testing the hypotheses elaborated in this research, a series of descriptive statistical analyses were performed with the help of the SPSS statistical program. Thus, the descriptive statistics together with the values of the Cronbach Alpha reliability coefficients calculated for each variable, as well as the correlation coefficients between these variables, are illustrated in Table 1.

TABLE 1. RESULTS OF DESCRIPTIVE STATISTICS AND PRELIMINARY ANALYSIS

\begin{tabular}{|c|c|c|c|c|c|c|c|}
\hline \multirow[b]{2}{*}{ Categories } & \multirow[b]{2}{*}{ Variables } & \multirow[b]{2}{*}{$\begin{array}{c}\text { Mean } \\
\text { (M) }\end{array}$} & \multirow[b]{2}{*}{$\begin{array}{c}\text { Standard } \\
\text { Deviation } \\
\text { (SD) }\end{array}$} & \multirow[b]{2}{*}{ Items } & \multirow[b]{2}{*}{$\begin{array}{c}\text { Cronbach's } \\
\text { Alpha }\end{array}$} & \multicolumn{2}{|c|}{ Correlations } \\
\hline & & & & & & $\begin{array}{c}\text { Customer } \\
\text { satisfaction } \\
\text { regarding } \\
\text { Online } \\
\text { Stores }\end{array}$ & $\begin{array}{c}\text { Customer } \\
\text { satisfaction } \\
\text { regarding } \\
\text { Physical } \\
\text { Stores }\end{array}$ \\
\hline \multirow{5}{*}{$\begin{array}{l}\text { Determinants } \\
\text { of the } \\
\text { purchase } \\
\text { decision }\end{array}$} & Informativeness & 4.038 & 0.920 & 4 & 0.896 & $0.460^{* *}$ & $0.298^{* *}$ \\
\hline & Social presence & 3.232 & 0.942 & 4 & 0.672 & $0.478^{\star *}$ & $0.277^{\star *}$ \\
\hline & Sensory marketing & 3.339 & 1.021 & 3 & 0.692 & $0.450^{* *}$ & $0.380^{* *}$ \\
\hline & Product type & 3.432 & 0.856 & 3 & 0.736 & $0.318^{* *}$ & $0.193^{*}$ \\
\hline & Brand trust & 3.363 & 0.966 & 3 & 0.734 & $0.432^{* *}$ & 0.168 \\
\hline \multicolumn{2}{|c|}{ Customer satisfaction regarding Online } & 3.607 & 0.887 & 11 & 0.929 & - & $0,482^{* \star}$ \\
\hline
\end{tabular}


Caraman, A., Racovița, M., Gora, A.A.

ONLINE AND PHYSICAL STORES: DETERMINANT FACTORS INFLUENCING THE PURCHASING DECISION AND CUSTOMER'S SATISFACTION

\begin{tabular}{|c|c|c|c|c|c|c|}
\hline \multicolumn{1}{|c|}{ Stores } & & & & & \\
\hline $\begin{array}{c}\text { Customer satisfaction regarding Physical } \\
\text { Stores }\end{array}$ & 3.464 & 0.831 & 11 & 0.901 & $0.482^{* *}$ & - \\
\hline
\end{tabular}

Source: created by authors based on survey results computed with IBM SPSS

Note: ${ }^{*}-p<0.05 ;{ }^{* *}-p<0.01$

As mentioned, the Cronbach Alpha coefficients were calculated using SPSS software before analysing the data and testing the research hypotheses. The Cronbach Alpha coefficient is a coefficient for measuring reliability or internal consistency and serves to illustrate whether two or more items analysed together measure the same as if they had been analyzed separately, or more precisely show how closely they are related between them a set of items analysed as a group. Generally, to be considered an acceptable coefficient of reliability, the values of the Cronbach Alpha coefficient must be above 0.70 in the exploratory stages of the research, and above 0.80 or 0.90 in the advanced stages of the research, while values lower than 0.60 indicate a lack of reliability (Hair Jr., Hult, Ringle, \& Sarstedt, 2017; Henseler, Ringle, \& Sinkovics, 2009; Hulland, 1999; Wolf, 2011). Analysing the values of the Cronbach Alpha coefficients in Table 1, it can be seen that they are above the recommended threshold value of 0.70 or are very close to this limit value, and the fact that the research is exploratory led us to keep these items in subsequent analyses. As an exception, the "Brand trust" factor was initially measured using four items, but because the value of the Cronbach Alpha coefficient obtained based on the four grouped items was very close to 0.60 , which indicates a lack of reliability, the "Cronbach's Alpha if item Deleted" column provided by the SPSS program was analysed and an item was removed. Following this elimination, the value of the Cronbach Alpha coefficient for the "Brand trust" decision factor became 0.734 , being above the limit value of 0.70 .

After calculating the Cronbach Alpha coefficients and evaluating the reliability of the variables, a series of descriptive statistics were calculated, and more precisely the mean and standard deviation of the variables analyzed in the present research. Thus, based on the results in Table 1, it can be seen that the most important factors of the purchase decision are represented by the factor "Informativeness" ( $M=4.038$; SD $=0.920)$ and the decision factor "Product type" ( $M=3.432 ; S D=0.856)$. On the other hand, in terms of the customers' satisfaction regarding online and physical stores, it can be seen that they are more satisfied with online stores $(M=3,607 ; S D=0.887)$.

In addition to the descriptive statistics and values of the Cronbach Alpha coefficients, in Table 1 were presented a series of correlations between the determinants of the purchasing decision and the degree of customers' satisfaction regarding online stores and, respectively, physical ones. Thus, it can be seen that regarding the correlations between the determinants of purchasing decisions, considered independent 
variables and the degree of customers' satisfaction regarding online stores, considered a dependent variable, all these indicate a positive and statistically significant because the associative $p$-values are less than 0.50 . On the other hand, out of the five determinants of the purchasing decision, only four of them indicate a statistically positive and significant correlation with the dependent variable of customers' satisfaction regarding physical stores.

\subsection{Testing Research Hypotheses}

Following the evaluation of the descriptive statistics and the performance of the preliminary analyses, the aim was to test the hypotheses formulated in the present research. In this sense, graphs, t-tests and multiple linear regression analyses were used to test the research hypotheses.

Thus, to test hypothesis 1, two questions were introduced in the questionnaire based on which it was determined whether the pandemic led to an increase in the number of customers in online stores compared to physical ones. To these questions: "How do you prefer to shop until the COVID-19 pandemic occurs?" And "How do you shop now?". The following distribution of answers was obtained (Figure 2):

\section{FIGURE 2. THE EFFECT OF THE PANDEMIC ON THE PURCHASING TREND OF CUSTOMERS}

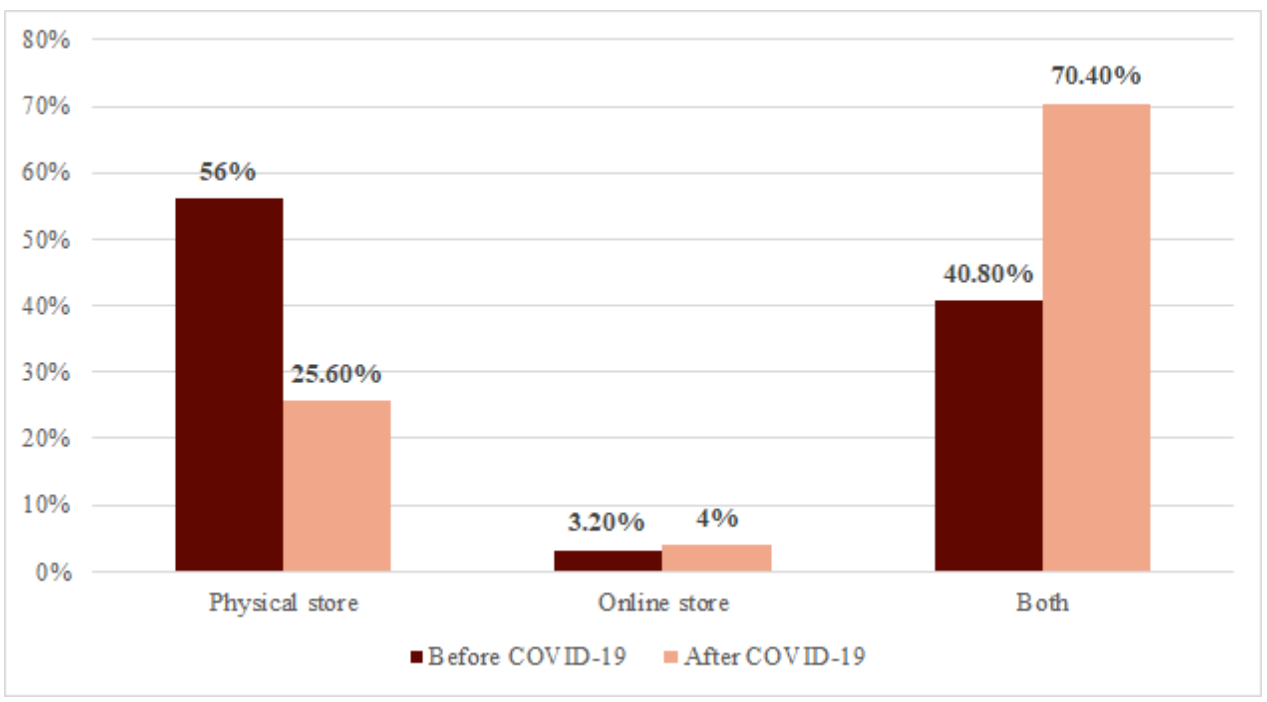

Source: created by authors based on survey results

The burgundy columns represent the shopping trends in relation to the purchasing environment of the products (physical, online or both) until the appearance of the pandemic, and the pink ones - after its establishment. According to Figure 2, it results that the percentage of purchases from the physical environment decreased by $30.4 \%$. In contrast to these results, there is no significant increase in users opting only for online shopping (this is only $0.8 \%$ ). Even though, customers have not completely moved into the digital/online environment, they have begun to consider online stores as an alternative to 
shopping, with the graph showing that the number of customers using both channels has increased by about half.

In conclusion, it can be stated that the pandemic has positively influenced the transition of online shopping by demonstrating the truthfulness of the hypothesis 1 . However, physical stores remain important to buyers, being the main way in which they shop. The results obtained are similar to studies in the literature which claim that people will always opt for a personalized customer service and a tactile experience that only physical stores can offer (Dauriz, Remy \& Sandri, 2014).

In order to test Hypothesis 2, five t-tests were used and performed for independent samples in order to compare how the determinants of the purchasing decision are perceived by women and men. The results of these tests are illustrated in Table 2.

TABLE 2. THE T-TEST RESULTS FOR INDEPENDENT SAMPLES

\begin{tabular}{|l|c|c|c|c|c|c|c|c|c|}
\hline \multirow{2}{*}{ Variables } & \multicolumn{2}{|c|}{$\begin{array}{c}\text { Women } \\
\text { (N= 85) }\end{array}$} & \multicolumn{2}{|c|}{ (N = 40) } & \multicolumn{2}{|c|}{ Levene test } & \multicolumn{3}{c|}{ t-test } \\
\cline { 2 - 12 } & M & SD & M & SD & F & p & t & df & p \\
\hline Informativeness & 4.000 & 0.931 & 4.119 & 0.902 & 0.032 & 0.858 & -0.672 & 123 & 0.503 \\
\hline Social presence & 3.268 & 0.889 & 3.156 & 1.056 & 1.040 & 0.310 & 0.615 & 123 & 0.540 \\
\hline Sensory marketing & 3.388 & 1.022 & 3.233 & 1.024 & 0.039 & 0.844 & 0.790 & 123 & 0.431 \\
\hline Product type & 3.400 & 0.846 & 3.500 & 0.883 & 0.298 & 0.586 & -0.608 & 123 & 0.545 \\
\hline Brand trust & 3.419 & 0.947 & 3.256 & 1.011 & 0.056 & 0.814 & 0.827 & 123 & 0.410 \\
\hline
\end{tabular}

Source: created by authors based on survey results computed with IBM SPSS

Note: $\mathrm{N}$ - number of respondents; $\mathrm{M}$ - mean; $\mathrm{SD}$ - standard deviation; $\mathrm{F}$ - Levene test value; $\mathrm{t}$ - $\mathrm{t}$-test value; $\mathrm{df}$ degree of freedom; $p$ - associated probability $p$-value

Before performing the t-tests for independent samples, a preliminary analysis was performed to verify the presumption of equality of variances, calculating the Levene test values. According to the results in Table 2 , it can be seen that the $F$ value of the Levene test has a statistically insignificant probability associated $p$ $(p<0.05)$ for all five determinants of the purchasing decision, which indicates that the assumption of equality of variants was not violated. In this regard, the results of the t-test related to this preliminary analysis were selected and interpreted.

Thus, the results obtained showed that there are no statistically significant differences in how the five determinants of the purchasing decision are perceived by women and men ( $p>0.05$ in all cases). However, the distinct averages between the two categories of respondents show that there are small differences in the perception of decision factors, namely: men seem to place more emphasis on the level 
of information and the type of product, while women give more and higher importance than men for social presence, sensory marketing and brand trust.

Based on these results, it can be concluded that hypothesis 2 has not been validated. This situation could be due to the small sample of interviewees, the significant difference between the genders of the respondents (68\% of them being women) and/or the transition to the online environment that changed the behavior of shoppers and the habit of buying.

To test the following two research hypotheses, namely hypothesis 3 and hypothesis 4 , multiple linear regression analysis was used. Preliminary to perform the multiple linear regression analysis, in order to diagnose the collinearity between the analysed variables, the values of the variance inflation factor (VIF) were calculated and analysed. The variance inflation factor (VIF) measures the extent of a correlation between one predictor and the other predictors in a model to determine the existence of multicollinearity. Regarding the values of the VIF indicator, in order to avoid collinearity problems, it is recommended that they be below the value of 10 (Gujarati, 2004; Robinson \& Schumacker, 2009), or even below the value of 5 (Hair Jr., Hult, Ringle, \& Sarstedt, 2017). On this line, as shown in Tables 4 and 5, the VIF values are below the recommended limit values, which indicates that there is no multicollinearity between the independent variables. Based on these results of the preliminary analysis, multiple linear regression analysis can be performed. Regarding the results of the regression analysis performed in this research, they were tested and interpreted based on a statistically significant level of 0.05 .

Thus, the specific results of the multiple linear regression analysis, related to the testing of hypothesis 3 , and more precisely to determine the extent to which the five determinants of the purchasing decision influence the satisfaction of buyers with respect to online stores, are presented in Table 3.

TABLE 3. MULTIPLE LINEAR REGRESSION ANALYSIS BETWEEN THE FACTORS OF THE PURCHASING DECISION AND THE DEGREE OF CUSTOMERS'SATISFACTION REGARDING THE ONLINE STORES

\begin{tabular}{|c|c|c|c|c|c|c|c|c|c|}
\hline \multirow{2}{*}{$\begin{array}{l}\text { Independent } \\
\text { Variables/ } \\
\text { Research } \\
\text { Hypotheses }\end{array}$} & \multirow{2}{*}{ B } & \multirow{2}{*}{$\beta$} & \multirow{2}{*}{$t$} & \multirow{2}{*}{$\mathrm{p}$} & \multicolumn{2}{|c|}{$\mathrm{Cl} 95 \%$} & \multicolumn{2}{|c|}{$\begin{array}{l}\text { Collinearity } \\
\text { Statistics }\end{array}$} & \multirow{2}{*}{$\begin{array}{l}\text { Supported/ } \\
\text { Not supported }\end{array}$} \\
\hline & & & & & Lower & Upper & Tolerance & VIF & \\
\hline Constant & 1.285 & & 3.810 & 0.000 & 0.617 & 1.953 & & & \\
\hline Informativeness (H3.a) & 0.265 & 0.275 & 3.055 & 0.003 & 0.093 & 0.437 & 0.679 & 1.473 & Supported \\
\hline Social presence (H3.b) & 0.196 & 0.208 & 1.890 & 0.061 & -0.009 & 0.401 & 0.455 & 2.200 & Not supported \\
\hline $\begin{array}{l}\text { Sensory marketing } \\
\text { (H3.c) }\end{array}$ & 0.129 & 0.148 & 1.300 & 0.196 & -0.067 & 0.325 & 0.424 & 2.358 & Not supported \\
\hline Product type (H3.d) & -0.138 & -0.134 & -1.259 & 0.211 & -0.356 & 0.079 & 0.491 & 2.039 & Not supported \\
\hline Brand trust (H3.e) & 0.197 & 0.214 & 2.091 & 0.039 & 0.010 & 0.383 & 0.526 & 1.901 & Supported \\
\hline
\end{tabular}




$$
R^{2}=0.343 ; F_{(5,119)}=12.431 ; p=0.000
$$

Source: created by authors based on survey results computed with IBM SPSS

Note: B - Unstandardized Coefficient; $\beta$ - Standardized Coefficient; $\mathrm{t}$ - $\mathrm{t}$ - Value; $\mathrm{p}$ - probability value; $\mathrm{Cl} 95 \%$ - $95 \%$

Confidence Intervals for $\mathrm{B}$; VIF - variance inflation factor; $\mathrm{R}^{2}=$ the coefficient of determination; $F-F$ statistic

Multiple linear regression analysis was used to assess the influence of all purchasing decision factors (level of information, social presence, sensory marketing, product typology, brand trust) on customer satisfaction with online stores. The regression model presented in Table 3 is a valid one because, statistically $F$ has an associated probability ( $p$ ) equal to 0.000 . Moreover, these results illustrated that these 5 variables are able to explain together $34.3 \%$ of the variation of buyers' satisfaction regarding online stores $\left(R^{2}=0.343\right)$. The intercept (Constant) represents the average level of customers' satisfaction regarding online stores if no other regressors would have an influence. At the same time, based on the $p$ values associated with the independent variables, it can be seen that two out of five determinants of the purchasing decision have a positively and statistically significant influence on the degree of customers' satisfaction regarding online stores, namely: information level $(\beta=0.275 ; t=3.055 ; p<0.05)$ and brand trust $(\beta=0.214 ; t=2.091 ; p<0.05)$. As a result, hypothesis 3 is only partially validated. The results obtained also support the results of other studies that present arguments regarding the importance of the level of product information in customers perception and in determining the purchasing decision (Katawetawaraks \& Wang, 2011; Luo and Bhattacharya, 2006) and which explain the influence of brand trust on buyers' behavior (Al-Alwan \& Al-Shirawi, 2015; Berry, 2000; Edwar, Diansari \& Winawati, 2018).

On the other hand, the aim of this research was to determine to what extent the determining factors of the purchasing decision influence the degree of buyers' regarding physical stores. In this regard, the results specific to the multiple linear regression, related to the testing of hypothesis 4 , are presented in Table 4.

TABLE 4. MULTIPLE LINEAR REGRESSION ANALYSIS BETWEEN THE FACTORS OF THE PURCHASING DECISION AND THE DEGREE OF CUSTOMERS' SATISFACTION REGARDING THE PHYSICAL STORES

\begin{tabular}{|c|c|c|c|c|c|c|c|c|c|}
\hline \multirow{2}{*}{$\begin{array}{c}\text { Independent } \\
\text { Variables/ } \\
\text { Research } \\
\text { Hypotheses }\end{array}$} & \multirow{2}{*}{ B } & \multirow{2}{*}{$\beta$} & \multirow{2}{*}{$\mathrm{t}$} & \multirow{2}{*}{$\mathrm{p}$} & \multicolumn{2}{|c|}{$\mathrm{Cl} 95 \%$} & \multicolumn{2}{|c|}{$\begin{array}{l}\text { Collinearity } \\
\text { Statistics }\end{array}$} & \multirow{2}{*}{$\begin{array}{l}\text { Supported/ } \\
\text { Not } \\
\text { supported }\end{array}$} \\
\hline & & & & & Lower & Upper & Tolerance & VIF & \\
\hline Constant & 2.189 & & 6.148 & 0.000 & 1.484 & 2.893 & & & \\
\hline Informativeness (H4.a) & 0.159 & 0.177 & 1.739 & 0.085 & -0.022 & 0.341 & 0.679 & 1.473 & Not supported \\
\hline Social presence $(\mathrm{H} 4 . \mathrm{b})$ & 0.021 & 0.024 & 0.190 & 0.850 & -0.196 & 0.237 & 0.455 & 2.200 & Not supported \\
\hline $\begin{array}{l}\text { Sensory marketing } \\
(\mathrm{H} 4 . \mathrm{C})\end{array}$ & 0.274 & 0.336 & 2.617 & 0.010 & 0.067 & 0.480 & 0.424 & 2.358 & Supported \\
\hline Product type (H4.d) & -0.079 & -0.081 & -0.681 & 0.497 & -0.308 & 0.151 & 0.491 & 2.039 & Not supported \\
\hline
\end{tabular}




\begin{tabular}{|c|c|c|c|c|c|c|c|c|c|} 
Brand trust (H4.e) & -0.023 & -0.027 & -0.233 & 0.816 & -0.219 & 0.173 & 0.526 & 1.901 & Not supported \\
\hline & $\mathbf{R}^{\mathbf{2}}=\mathbf{0 . 1 6 7 ;} \mathbf{F}_{(5,119)} \mathbf{4 . 7 6 3 ;} \mathbf{p}=\mathbf{0 . 0 0 1}$ \\
\hline
\end{tabular}

Source: created by authors based on survey results computed with IBM SPSS

Note: B - Unstandardized Coefficient; $\beta$ - Standardized Coefficient; $\mathrm{t}$ - $\mathrm{t}$ - Value; $\mathrm{p}$ - probability value; CI 95\% - 95\%

Confidence Intervals for $\mathrm{B}$; VIF - variance inflation factor; $\mathrm{R}^{2}=$ the coefficient of determination; $F-F$ statistic

Analyzing the results of multiple linear regression, highlighted in Table 4, we can see that the value $F=$ 4.763 has a related probability statistically significant $(p<0.05)$, which makes the regression model to be valid. The coefficient of determination $\left(R^{2}=0.167\right)$ shows that $16.70 \%$ of the variability of the dependent variable depends on the independent variables. In other words, the five determining factors of the purchasing decision are able to explain, together, $16.70 \%$ of the variance of the degree of buyers satisfaction regarding the physical stores. Moreover, analyzing the independent variables, it can be seen that the degree of shoppers' satisfaction regarding physical stores is positively and significantly influenced only by the sensory marketing decision factor $(\beta=0.336 ; t=2.617 ; p<0.05)$. The other regressors do not have a significant influence on the dependent variable because the $p$-values associated with them are greater than 0.05 .

On this line, hypothesis 4 was only partially confirmed. These results stand up the results Katawetawaraks \& Wang's study (2011) who consider the intangibility of online product a factor that prevents the decision to buy in online stores and supports the purchase in physical stores (offline).

Comparing the results of the influence of purchasing decision makers on buyers' satisfaction with online and physical stores, the following can be highlighted:

1. Customers' satisfaction who shop in physical stores is influenced by sensory marketing: smells, sounds, textures.

2. Customers' satisfaction who shop in online stores is influenced by the level of existing information and trust in the brand.

These discoveries can be used by managers to create a strategy to attract a larger number of customers depending on the adapted business model.

\section{CONCLUSIONS}

In this research, it was intended to highlight how customers' buying trends were affected by the transition to the online environment imposed by the COVID-19 pandemic. In this regard, a questionnaire-based survey was used in which 125 people participated, of which 40 are men and 85 women, aged between 18 and over 50 years, with an average income ranging between 500 and over 4500 RON. Following data collection, a series of descriptive statistical analyzes and a series of preliminary analyzes were performed, 
and the hypotheses formulated in this research were tested by means of t-tests for independent samples and multiple linear region analysis.

Comparing the purchasing of people before and after the pandemic, it was found that several of them began to consider online stores as a shopping alternative. However, physical stores remain important to customers as the main way they shop. In this regard, in order to create a complete shopping experience, it would be useful for managers to use a combination of online and physical stores to sell their products.

When the different perception of purchasing decision factors was considered (level of information, social presence, sensory marketing, product typology and brand trust) from the two sexes, it was not identified or particularly significant. It can be assumed that this is due to the transition to the online environment, which has led to the disappearance of gender barriers. These findings could lead business managers to not focus on women only and pay attention to men, especially in the online environment.

Another important finding was that satisfaction in the physical environment is influenced by variables other than the online environment. In this sense, shoppers are more satisfied with sensory marketing when shopping in physical stores, while in online stores there is a significant satisfaction created by the level of information presented about a product, but also trust in the brand. Even if they seem unnecessary at first glance, the smell in the shops, the background sounds or the arrangements of the products contribute to the creation of satisfied customers who will definitely return. In contrast, e-stores must invest in the development of an accessible platform with clear and structured information, and provide a high quality service that meets the required standards.

The limitations of the current study are represented by the small sample size and the homogeneity of the surveyed population (unbalanced towards young people). Marketing policy needs all demographic categories of people, even if maybe young people are more interested in shopping, there is no need to neglect the other age groups.

As for future research directions, they could aim at introducing other variables, such as customer loyalty or perceived quality and analysis of the influence of decision makers on them; research into how decisionmakers are perceived to depend on respondents' income tranches; and exploring how customers perceive a combination of physical and online stores. Also, the study did not take into consideration demographic factors, such as age, occupation, income, living environment, location of the physical store compared to the opportunity to buy online, etc., as a variable that can cause buyers to buy products either online or physical. It is necessary to study and analyze the hypothesis according to which for both environments there may be different decision-making factors, but also similar ones that could contribute to the development of the business environment both for entrepreneurs and for the satisfaction of existing 
demand. Also, the authenticity of the results of research conducted up to the pandemic in the current context can be verified to identify which variable could influence buyers to be studied.

\section{REFERENCES}

Al-Alwan, M. \& Al-Shirawi, A.M. (2015). An Investigation of Factors Influencing Online Shopping: An Explanotory Study in the Kingdom of Bahrain'. Int. J. Innovation and Knowledge Management in the Middle East and North Africa. 4(2): 86-94.

Berry, L.L. (2000). Cultivating service brand equity. Academy of Marketing Science. 28(1): 128-137. DOI:10.1177/0092070300281012.

Brynjolfsson, E., Hu, Y. \& Rahman, M.S. (2009). Battle of the retail channels: How product selection and geography drive cross-channel competition. Management Science Informs. 55(11): 1755-1765. DOI:10.1287/mnsc.1090.1062.

ContentEngine LLC traducere. (2020). U.S. online shopping revolution to endure after pandemic. CE Noticias Financieras. ContentEngine LLC. U.S., Miami. Retrieved May 20, 2021, from https://search-proquest-com.am.e-nformation.ro/wire-feeds/u-s-online-shopping-revolution-endureafter/docview/2405811844/se-2?accountid=136549.

Dauriz, L., Remy, N. \& Sandri N. (2014). Luxury shopping in the digital age. Perspectives on retail and Consumers Goods. McKinsey \& Company. Retrieved May 20, 2021, from https://www.mckinsey.com/industries/retail/our-insights/luxury-shopping-in-the-digital-age.

Edwar, M., Diansari, R.A.A. \& Winawati, N. F. (2018). The factors that affecting the product purchasing decision through online shopping by students of Surabaya state university. International Journal of Educational Research Review. 3(4): 54-64.

Greelane.com. (2019). Marketing psihologic: cum ne vând simțrile. Retrieved Aprilie 5, 2021, from https://www.greelane.com/ro/umanistic\%C4\%83/probleme/sensory-marketing-4153908.

Gujarati, D.N. (2004). Basic Econometrics. Fourth Edition. New York: McGraw-Hill.

Hair Jr., J. F., Hult, G. T., Ringle, C. M., \& Sarstedt, M. (2017). A Primer on Partial Least Squares Structural Equation Modeling (PLS-SEM) (2nd edition). SAGE.

Henseler, J., Ringle, C. M., \& Sinkovics, R. (2009). The Use of Partial Least Squares Path Modeling in International Marketing. New Challenges to International Marketing (Advances in International Marketing), 277-319.

Hill, N., Brierley, J. \& MacDougall, R. (2003). How to Measure Customer Satisfaction, 2nd ed. Gower Pub Co. Great Britain. London. DOI:10.4324/9781315253107.

Hulland, J. (1999). Use of Partial Least Squares (PLS) in Strategic Management Research: A review of Four Recent Studies. Strategic Management Journal. 20: 195-204.

Jain, S. \& Werth, D. (2019). Current State of Mixed Reality Technology for Digital Retail: A Literature Review. eCommerce and Consumer Behavior, $\mathrm{HCl}$ in Business. Government and Organizations (pp.2237). USA, California. DOI:10.1007/978-3-030-22335-9_2.

Jones, C. \& Tyko, K. (2020). Shopping malls were struggling before COVID-19 and now have more empty stores: What's next after the pandemic?. USA Today (Online). U.S., Arlington. Retrieved 
Caraman, A., Racovița, M., Gora, A.A.

ONLINE AND PHYSICAL STORES: DETERMINANT FACTORS INFLUENCING THE PURCHASING DECISION AND

CUSTOMER'S SATISFACTION

April 5, 2021, from https://search-proquest-com.am.e-nformation.ro/newspapers/shopping-mallswere-struggling-before-covid-19/docview/2473313727/se-2?accountid=136549.

Katawetawaraks, C. \& Wang, C. (2011). Online shopper behavior: Influences of online shopping decision. Asian journal of business research. 1(2): 66 - 74. DOI 10.14707/ajbr.110012.

Luo, X. \& Bhattacharya, C.B. (2006). Corporate social responsibility, customer satisfaction, and market value. Journal of Marketing. 70(4): 1-18. DOI:10.1509/jmkg.70.4.001.

McNealy, M.R. (1993). Making Customer Satisfaction Happen, 1st ed. Springer Netherlands. USA, Boston.

Robinson, C. \& Schumacker, R.E. (2009). Interaction Effects: Centering, Variance Inflation Factor, and Interpretation Issues. Multiple Linear Regression Viewpoints. 35(1): 6-11.

Wolf, S. (2011). Management Accountants' Business Orientation and Involvement in Incentive Compensation: Empirical Results from a Cross-Sectional Survey. Berlin: Controlling \& Business Accounting. Peter Lang International Academic Publishers.

Yan, X. \& Dai, S. (2009). Consumer's Online Shopping Influence Factors and Decision-Making Model. In SIGeBIZ track of the Americas Conference on Information Systems (pp. 89-102). Springer, Berlin, Heidelberg. 